\title{
Defecting 2'-O methyltransferase as a novel strategy for live attenuated vaccine development
}

Volume 3 Issue I - 2016

\author{
Hui Cai \\ The Ohio State University, USA
}

\section{Editorial}

The 5' ends of almost eukaryotic cellular mRNAs possess Cap 0 structure with an N-7 methyl-guanosine moiety linked to the first nucleotide of the nascent mRNA via a 5'-5' inverted triphosphate bridge. And in higher eukaryotes, Methylation of cellular mRNA occurs additionally at the 2'-O position of the penultimate to form the Cap1 structure (7mGpppNm-) and antepenultimate to form Cap2 structure (7mGpppNmNm-).

The cap structure ensures the transcript to escape a variety of cellular 5'-3' exonucleases and promote recognition of eIF4E for translation. Besides, RNA capping was also involved in other cellular processes such as RNA splicing and exports. ${ }^{1-3}$ Vast majority of viruses replicate in the cytoplasm, and also they failed to access the host capping machinery in the nucleus. Therefore, they evolved their own capping apparatus, and a diversity of mechanisms which leads to the same RNA cap structure are being deciphered. ${ }^{4-8}$

In the conventional pathway, the cap structure is added to the nascent 5'-triphosphate mRNA in a series of reactions. First, the 5'-triphosphate of the nascent RNA is hydrolyzed the RNA triphosphatase (RTPase), and the $\gamma$-phosphate will removed to leave 5'-diphosphate RNA; Second, an RNA guanylyltransferase (GTase) transfer a GMP moiety to $\mathrm{ppN}$ - to yield the cap core structure GpppNin 5' -5 ' orientation. Third, the core cap structure is methylated on the $\mathrm{N}-7$ position of its guanine by an RNA guanine N7 methyltransferase (N7-MTase) to generate the minimal Cap 1 structure. Lastly, further Methylation by ribose 2'-O methyltransferase occurs at the 2'-position of the first transcript nucleoside (Cap 1) and the second nucleotide (Cap 2).

Recently, Zust R, et al. ${ }^{9}$ demonstrated the 2'-O-methylation of mRNA protected viral RNA from recognition by Mda5 and thus prevented production of type I interferon in virus infected cells, and also 2'-O-methylation of viral mRNA contributes to evasion of the interferon-mediated restriction of viral replication. Therefore, the human and mouse coronavirus mutants lacking 2'-O-methylatransferase activity induced higher expression of type I interferon. ${ }^{9}$

With this in mind, targeting viral 2'-O-methylatransferase might provide a new and valid rational approach for a live attenuated vaccine design. In 2013, dengue virus mutants lacking 2'-O-methyltransferase activity are attenuated in mice and rhesus monkeys, but elicit a strong adaptive immune response. Monkeys immunized with a single dose of the mutant virus showed $100 \%$ sero-conversion even when a dose as low as 1,000 plaque forming units. Animals were fully protected against a homologous challenge..$^{10}$ Very recently, Menachery V, et al. ${ }^{11}$ generated mutants in SARS-CoV 2-O'-methylatransferase by replacing critical residues within the conserved catalytic KDKE motif. Interesting, the mutants remained replication competent, but

\begin{abstract}
Correspondence: Hui Cai, The Ohio State University, 1925 Coffey Road, Rm 219, Columbus, OH 43210, USA, Tel 469-7661765, Email chncaihui@gmail.com
\end{abstract}

Received: January 12, 2016 | Published: January 13, 2016

these mutants were attenuated in IFN competent cells, had reduced pathogenesis and complete protected mice from lethal challenge in vivo. ${ }^{11}$

Whether the balance between low virulence and high immunogenicity is achieved in humans by 2'-O-MTase mutants remains to be elucidated. However, current data demonstrated that targeting viral 2'-O-methyltransferase as a valid strategy for rapid, rational vaccine design for majority viruses encoding their own 2'-O-methyltransferase.

\section{Acknowledgments}

None.

\section{Conflicts of interest}

None.

\section{References}

1. Filipowicz W, Furuichi Y, Sierra JM, et al. A protein binding the methylated 5'-terminal sequence, $\mathrm{m} 7 \mathrm{GpppN}$, of eukaryotic messenger RNA. Proc Natl Acad Sci U S A. 1976;73(5):1559-1563.

2. Schibler U, Perry RP. The 5'-termini of heterogeneous nuclear RNA: a comparison among molecules of different sizes and ages. Nucleic Acids Res. 1977;4(12):4133-4149.

3. Darnell JE. Transcription units for mRNA production in eukaryotic cells and their DNA viruses. Prog Nucleic Acid Res Mol Biol. 1979;22:327-353.

4. Weber F, Haller O, Kochs G. Nucleoprotein viral RNA and mRNA of Thogoto virus: a novel cap-stealing mechanism in tick-borne orthomyxoviruses? J Virol. 1996;70(12):8361-8367.

5. Vasiljeva L, Merits A, Auvinen P, et al. Identification of a novel function of the alphavirus capping apparatus. RNA 5'-triphosphatase activity of Nsp2. J Biol Chem. 2000;275(23):17281-17287. 
6. Liu L, Dong H, Chen H, et al. Flavivirus RNA cap methyltransferase: structure, function, and inhibition. Front Biol (Beijing). 2010;5(4):286-303.

7. Decroly E, Ferron F, Lescar J, et al. Conventional and unconventional mechanisms for capping viral mRNA. Nat Rev Microbiol. 2012;10(1):51-65.

8. Ogino T, Banerjee AK. An unconventional pathway of mRNA cap formation by vesiculoviruses. Virus Res. 2011;162(1-2):100-109.

9. Züst R, Cervantes-Barragan L, Habjan M, et al. Ribose 2'-Omethylation provides a molecular signature for the distinction of self and non-self mRNA dependent on the RNA sensor Mda5. Nat Immunol. 2011;12(2):137-143.
10. Züst R, Dong H, Li XF, et al. Rational design of a live attenuated dengue vaccine: 2'-o-methyltransferase mutants are highly attenuated and immunogenic in mice and macaques. PLoS Pathog. 2013;9(8):e1003521.

11. Menachery VD, Yount BL, Josset L, et al. Attenuation and restoration of severe acute respiratory syndrome coronavirus mutant lacking 2'-0methyltransferase activity. J Virol. 2014;88(8):4251-4264. 